\title{
Mechanical Characterization of a Au Coated Carbon Nanotube Multi-layered Structure
}

\author{
Hong Liu, John W. McBride, Suan Hui Pu \\ University of Southampton Malaysia Campus \\ Johor, Malaysia \\ Email: hl1v13@ soton.ac.uk
}

\author{
Michael P. Down, Liudi Jiang \\ Faculty of Engineering and the Environment \\ University of Southampton \\ Southampton, UK
}

\begin{abstract}
Multiwalled Carbon Nanotube (MWCNT) -coated surfaces have been proved to be able to provide stable resistance for the electrical contact under low force conditions since they can offer a compliant support for the conducting gold layer. However, the contact mechanics of the Au/MWCNTs composite have not been understood. In this study, a finite element multilayered contact model was developed, in which the top layer was modeled as a composite and under layer was modeled as CNT forest. The study shows that this complex surface is best modeled as a multi-layered structure. The model is optimized and validated with nano-indenter data. The model can help to better understand the structure and material properties of Au/CNTs surfaces, and can provide guidance to optimize the surface in terms of contact resistance performance in MEMS switches.
\end{abstract}

Keywords- carbon nanotubes, multi-layered, contact mechanics, finite element modeling

\section{INTRODUCTION}

For MEMS microswitches, a stable and low contact resistance is required. Researchers have investigated different materials to improve the reliability of microswitches and retain low electrical resistivity at the same time. Commonly used materials for ohmic microswitches include gold, palladium and platinum [1], ruthenium [2] and rhodium [3], gold-alloy, etc.[4], but the weakness of such materials is that they are relatively soft and wear easily. Other materials like silicon carbide and diamond films have low electrical conductivity and are unsuitable for electrical contact application [5]. The application of multi-walled carbon nanotubes (MWCNTs) as contact surfaces was first investigated in [6], and then improved with gold-coated surfaces where a forest of CNTs is used to create a compliant under layer to the metallic film. Early studies [7-10] show that a carbon nanotube coated surface has potential as a contact material for MEMS switches, and can significantly improve the device lifetime.

Individual CNT show a very high elastic modulus [11-13], but when they grow together as vertical aligned forest, they present a compliant mechanical response to the compressive load/surfaces, and the effective modulus is reduced by several orders of magnitude [14]. Most of studies in the literature suggest that this is due to bending and buckling of CNT as well as the variation of CNT density throughout the forest height [15], while other studies showed that the inherent waviness of individual CNT is a significant cause for reducing the effective modulus of vertical CNTs forest [14].

The nanoindentation technique has been shown to be an excellent technique to measure the mechanical properties of the effective modulus of aligned vertical CNTs film $[14,16]$. However, gold-coated CNTs (Au/CNTs) surface presents more complicated features, and added complexity to research. Scanning electron microscope (SEM) images showed that the gold layer did not form a neat film, but penetrated into the CNTs forest [17-18].

The mechanical properties of Au/CNTs composite have been investigated with nanoindentation technique [19]. Based on the nanoindentation test results, this paper investigates the mechanical behavior of Au/CNTs composite and its contact mechanics by finite element modeling (FEM). The purpose is to develop a FE model of this unique composite, so that the surfaces can be optimized in terms of contact resistance performance in a MEMS switching device.

\section{SAMPLE DESCRIPTION AND NANOINDENTATION TEST SETUP}

To produce $\mathrm{Au} / \mathrm{CNT}$ s composite, a seed layer of $\mathrm{Al}_{2} \mathrm{O}_{3}$ of $1.5 \mathrm{~nm}$ is sputtered initially on $\mathrm{Si}$ wafer, and followed by a catalyst layer of Fe of $10 \mathrm{~nm}$. The "forest" of CNT is grown using thermal chemical vapor deposition (CVD). In the CVD process, the flow rate and temperature $875^{\circ} \mathrm{C}$ is kept constant and the time of growth is used to control the length of the CNTs. Three lengths of CNTs forest were grown, namely: 30 $\mu \mathrm{m}, 50 \mu \mathrm{m}$, and $80 \mu \mathrm{m}$. A gold layer was then sputtered onto the nanotube forest. Three thicknesses of gold, $300 \mathrm{~nm}, 500$ $\mathrm{nm}$ and $800 \mathrm{~nm}$ were coated, and all together generate a matrix of 9 different layer configuration of Au/CNTs samples. One of the composite is shown in Fig. 1, where the Au coating is shown to conform to the top surface of the CNT forest and diffuses into the structure; penetration depth can be up to $4 \mu \mathrm{m}$ [17].

Nanoindentation tests were carried out with the MicroMaterials Nanotest Vantage. As the Berkovich tip would pierce the gold film and separate the CNTs [19], the test were performed with a $200 \mu \mathrm{m}$ radius diamond indenter tip. Quasistatic and dynamic impulse testing were both accomplished, only quasi-static test results were used in the modeling.

For each layer configuration, 2 samples were tested and the results were averaged. Each sample was subjected to four loads of $0.25 \mathrm{mN}, 0.5 \mathrm{mN}, 0.75 \mathrm{mN}$ and $1 \mathrm{mN}$, and repeated 
10 times for each set. However, some of the samples failed during loading at $1 \mathrm{mN}$, so the tests with load up to $0.75 \mathrm{mN}$ are studied in the paper. The elastic modulus and hardness are calculated automatically by the system with the model of Oliver and Pharr [20]. Hardness is calculated by classical theory:

$$
H=P_{\max } / A
$$

where $H$ is the hardness, $P_{\max }$ is the maximum load and $A$ is the projected contact area.

Effective elastic modulus is evaluated by (2):

$$
\begin{gathered}
E_{r}=\frac{\sqrt{\pi}}{2 \beta} \frac{S}{\sqrt{A\left(h_{c}\right)}} \\
\frac{1}{E_{r}}=\frac{1-v_{i}^{2}}{E_{i}}+\frac{1-v^{2}}{E}
\end{gathered}
$$

where $E_{\mathrm{r}}$ is the effective elastic modulus defined by (3). $\beta$ is a constant depending on the geometry of the indenter. $S$ is the slope of the curve during the initial stages of unloading, also named contact stiffness. $h_{\mathrm{c}}$ is the depth along which contact is made between the indenter and the specimen. $E$ and $v$ are the Young's modulus and Poisson's ratio for the specimen, and $E_{\mathrm{i}}$ and $v_{\mathrm{i}}$ are the values for the indenter.

In the nanoindentation tests, the projected area is calculated by the system with area function as described in [21] and $h_{\mathrm{c}}$ is evaluated with a cut off of the maximum indent depth. The cut-off value was mostly set to $40 \%$, which is chosen based on the shape and reliability of the curve itself.

During indentation the indenter occasionally encountered a void or pocket in the CNTs forest where the CNTs did not grow, therefore these curves are removed for accuracy. Fig. 2 shows the force-depth curves for sample $300 \mu \mathrm{m}$ CNTs coated with $300 \mathrm{~nm} \mathrm{Au}$. The data show a degree of variation, thus material properties were calculated based on the averaged curves with the anomalies removed. It should be kept into mind that the properties were evaluated by considering the composite as a single continuum material, but this is not the case of Au/CNTs composite. However, these values demonstrate the response in terms of different layer configuration and the indenter depth, and can provide experimental references for the FE modeling.

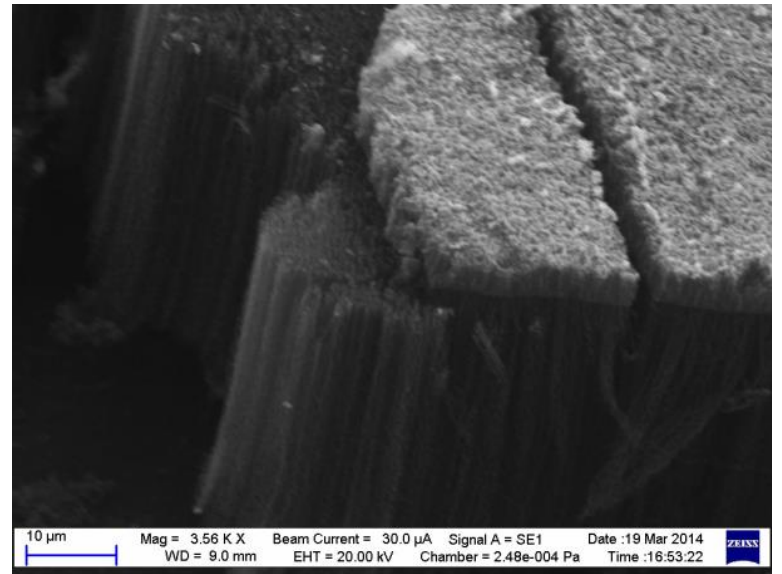

Fig. 1. Sample $30 \mu \mathrm{m}$ CNTs with $300 \mathrm{~nm}$ coated-gold: $4-5 \mu \mathrm{m}$ of $\mathrm{Au}$ penetrates into MWCNTs which is on a Si substrate.

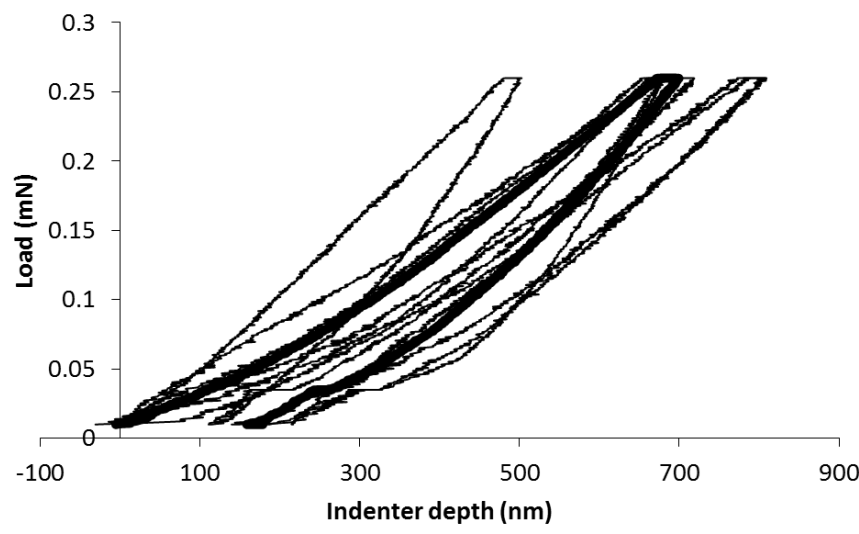

Fig. 2. Nanoindentation results for the composite $30 \mu \mathrm{m}$ CNTs coated with $300 \mathrm{~nm}$ gold, under $0.25 \mathrm{mN}$. The thin lines are experimental results, and the thick line is average curve.

\section{FINITE ELEMENT MODELING}

Finite element simulations were performed with ANSYS 14.5. The contact model includes a diamond hemisphere of $200 \mu \mathrm{m}$ radius, making contact with gold coated CNTs composite, as shown in Fig. 4. Seed layer and catalyst layer are not included in the modeling. Material properties for diamond are elastic modulus $E=1140 \mathrm{GPa}$ and Poisson's ratio $v=0.07$ [22].

\section{A. Material asssumption for Au/CNTs composite}

Two assumptions are proposed to model the Au/CNTs structure. In both assumptions, the Au/CNTs composite is treated as continuum material despite the specific form of nanotubes and the possible relative motion between individual shells or tubes. It has been validated that this continuum assumption can be an acceptable simplification for the purpose of moduli predictions [23].

1) Assumption 1: assuming the composite as a single material

As a first approximation, the Au/CNTs composite is modeled as a single continuum material, and its material properties are taken from the nanoindentation test. 
Experiments shows that there is residual deformation after unloading (see Fig. 7 and Fig. 8 for example) so the material properties for the composite is assumed to be elastic-plastic and strain hardening is included. The material model MISO (multi-linear isotropic hardening) is defined in ANSYS. Since only elastic modulus and hardness are extracted from the indentation tests, several assumptions are made for setting material properties in finite element modeling:

- Yield strength is assumed as $\sigma_{\mathrm{y}}=H / 2.8$ [24], ultimate strength $\sigma_{\mathrm{u}}=1.1 \times \sigma_{\mathrm{y}}$.

- Tangent modulus during elastic-plastic deformation (region II in Fig. 3) is: $E_{\mathrm{t}}=5 \% \times E$ [24]

- Poisson's ratio is set as the same as gold: $v=0.42$.

Fig. 3 shows a stress-strain curve of materials, and I, II and III zones cover elastic, elastic-plastic and plastic deformation respectively. Table I lists all material properties for different samples in FE models, the data are based on the tests at load of $0.25 \mathrm{mN}$. Previous simulations were carried out with tangent modulus varying from 0 to $10 \% \times E$, which are the extreme case for most materials [24], the difference in forcedisplacements results was less than $8 \%$ for $0.25 \mathrm{mN}$ load, so $5 \% \times E$ was used as tangent modulus for all elastic-plastic material property settings.

2) Assumption 2: assuming the composite as a multilayered structure

The nanoindentation tests showed that the mechanical behavior of $\mathrm{Au} / \mathrm{CNT}$ s composite vary with the indenter depth and the thickness of Au and CNTs, as shown in table 1, which reveals a multi-layered structure behavior [25], so the second assumption considers the $\mathrm{Au} / \mathrm{CNTs}$ composite as a multilayered structure.

Considering the sputtered gold does not form a neat layer, but penetrates into the CNTs forest (Fig. 1), the top layer is not modeled as a gold film, but as a mixed material, labeled AuCNT layer herein, the penetration depth is taken as the thickness of AuCNT layer. The bottom layer is modeled as pure CNTs forest.

The indentation depth $(0.2 \mu \mathrm{m}$ to $8 \mu \mathrm{m}$, see Fig. 10 and Fig. 11 for example) is usually larger than $0.2-0.3$ of the penetration depth (2-4 $\mu \mathrm{m}$ or more), so the influence of CNTs under layer on the mechanical behavior of the composite cannot be ignored [26], and the measured material properties from nanoindentation tests are the combined effect of AuCNT top layer and CNTs under layer, and there is no experimental data for material properties of each layer. Based on the indentation tests, we took the approximate values, as:

- For AuCNT top layer, the material properties are from the hardest sample (thickest Au and shortest CNTs) at low load, i.e. the sample $30 \mu \mathrm{m}$ CNTs $/ 0.8 \mu \mathrm{m}$ Au at $0.25 \mathrm{mN}$ (sample 3 in Table I). The indenter depth is $148 \mathrm{~nm}$ at $0.25 \mathrm{mN}$, so that the measurement captured mostly the features of the top layer.

- $\quad$ For CNTs forest under layer, material properties are from the softest sample (thinnest $\mathrm{Au}$ and tallest CNTs) at higher load, i.e. $80 \mu \mathrm{m} \mathrm{CNTs} / 0.3 \mu \mathrm{m} \mathrm{Au}$ at $0.75 \mathrm{mN}$. The indenter depth can be up to $8 \mu \mathrm{m}$, which is the largest depth among the tests, and is assumed to give the CNTs forest properties.

Table II lists the material properties for Assumption 2. The first two rows are the original setting and the others are the varied values in the modeling. It should be clarified that since the nano-indenter suffered from dispersion of the CNTs and the hardness reached the lowest limit of the capabilities of the machine, so no measured data for pure CNTs were obtained. However, the elastic modulus of CNTs forest matches well with the measured values in the literature, such as: effective modulus of $0.12-0.27 \mathrm{MPa}$ for $150 \mu \mathrm{m}$ MWCNTs in [14], and $8 \mathrm{MPa}$ for $100 \mu \mathrm{m}$ MWCNTs in [27]. As CNTs present a super-compressible behavior [15], CNTs forest under layer is considered to deform elastically only, while the top layer AuCNT is modeled as an elastic-plastic material. Poisson's ratio of CNTs forest is set as 0 as in $[16,28]$, and 0.21 for top layer (average of $\mathrm{Au}$ and CNTs). Though the values of Poisson's ratio are not certain, it was found that the Poisson's ratio had a weak influence on the mechanical behavior [25, 29]. Also, previous simulations showed that with the value of Poisson's ratio changed from 0 to 0.42 , the relative difference for the displacement was less than $4 \%$.

TABLE I. MATERIAL PROPERTIES IN FE MODELS: ASSUMPTION 1, CONSIDERING THE COMPOSITE AS A SINGLE ELASTIC-PLASTIC MATERIAL, THE POISSON's RATIO IS 0.42. THE DATA ARE BASED ON FORCE 0.25 MN

\begin{tabular}{|c|c|c|c|}
\hline $\begin{array}{c}\text { Sample } \\
\text { number }\end{array}$ & $\begin{array}{c}\text { Composite } \\
\text { CNTs }(\boldsymbol{\mu m}) \\
\text { /Au }(\boldsymbol{\mu m})\end{array}$ & $\begin{array}{c}\text { Elastic } \\
\text { modulus } \\
\boldsymbol{E}(\mathbf{M P a})\end{array}$ & $\begin{array}{c}\text { Hardness } \\
\boldsymbol{H} \\
(\mathbf{M P a})\end{array}$ \\
\hline 1 & $30 / 0.3$ & 66.483 & 0.6398 \\
\hline 2 & $30 / 0.5$ & 723.96 & 1.9464 \\
\hline 3 & $30 / 0.8$ & 887.455 & 2.8933 \\
\hline 4 & $50 / 0.3$ & 1.844 & 0.0352 \\
\hline 5 & $50 / 0.5$ & 21.925 & 0.2815 \\
\hline 6 & $50 / 0.8$ & 83.227 & 1.0522 \\
\hline 7 & $80 / 0.3$ & 1.2909 & 0.0286 \\
\hline 8 & $80 / 0.5$ & 2.1695 & 0.0383 \\
\hline 9 & $80 / 0.8$ & 23.012 & 0.2912 \\
\hline
\end{tabular}

TABLE II. MATERIAL PROPERTIES IN FE MODELS: ASSUMPTION 2, CONSIDERING THE COMPOSITE AS A MULTI-LAYERED STRUCTURE: AUCNT AS TOP LAYER, AND CNTS FOREST AS UNDER LAYER. THE FIRST TwO ROWS ARE THE ORIGINAL VALUES, WHILE OTHERS ARE VARIED SETTINGS IN MODELS. TOP5 IMPLIES ORIGINAL $E$ AND $H$ VALUES OF TOP LAYER MULTIPLIED BY 5, LIKEWISE FOR OTHERS.

\begin{tabular}{|c|c|c|c|c|}
\hline Model & Layer & $\begin{array}{c}\text { Elastic } \\
\text { modulus } \\
E(\mathrm{MPa})\end{array}$ & $\begin{array}{c}\text { Hardness } \\
\boldsymbol{H} \\
(\mathrm{MPa})\end{array}$ & $\begin{array}{c}\text { Poisson's } \\
\text { ratio } v\end{array}$ \\
\hline 1 & $\begin{array}{l}\text { Top layer } \\
\text { AuCNT }\end{array}$ & 887.455 & 2.8933 & 0.21 \\
\hline 2 & $\begin{array}{c}\text { Under layer } \\
\text { CNTs }\end{array}$ & 0.726 & & $\begin{array}{c}0[28], \\
{[16]}\end{array}$ \\
\hline 3 & $\begin{array}{l}\text { Top layer } \\
\text { Top1.4 }\end{array}$ & 1242.44 & 4.05 & 0.21 \\
\hline 4 & $\begin{array}{l}\text { Top layer } \\
\text { Top5 }\end{array}$ & 4435.275 & 14.4665 & 0.21 \\
\hline 5 & $\begin{array}{c}\text { Under layer } \\
\text { CNTs5 }\end{array}$ & 3.63 & & 0 \\
\hline 6 & $\begin{array}{c}\text { Under layer } \\
\text { CNTs10 }\end{array}$ & 7.26 & & 0 \\
\hline
\end{tabular}




\section{B. Description of finite element model}

For modeling of Assumption 1, the Si substrate is modeled as a block with length=width $=800 \mu \mathrm{m}$ and thickness of $275 \mu \mathrm{m}$ (see Fig. 4). It has been validated that using a larger size for the composite $(L, W>800 \mu \mathrm{m})$ does not alter the results.

For modeling of Assumption 2, only a quarter of the hemisphere and substrate is used to reduce the computational time (see Fig. 5).

The meshing in contact models is the same as in [30], both deformable bodies are modeled using 3D tetrahedral solid element SOLID187, which has special features of plasticity, stress stiffening, large deflection and large strain capabilities. 3D surface-to-surface contact element CONTA174 and target element TARGE174 are used to mesh the contact surfaces of substrate and hemisphere respectively. These elements are selected to consider large deflection and nonlinear behavior of contact asperities. The meshing near the contact region is refined to capture the contact accurately, while meshing of the rest of volume is coarse (Fig. 5).

As boundary conditions, the bottom surface of the lower volume is fixed. For all nodes of top surface of the hemisphere, the degree of freedom (DOF) UZ is coupled using "CP" command, so that they have the same displacement in the $\mathrm{Z}$ direction only, and uniform pressure is applied vertically on the top surface of hemisphere. A loading-unloading cycle is applied, with increment/decrement of $0.025 \mathrm{mN}$, i.e. for a load of $0.25 \mathrm{mN}$, it is 10 steps for loading and 10 steps for unloading.

Especially, for the model with reduced geometry, the nodes on the symmetric surface cannot move along the normal axis of the symmetric surface, i.e. the displacement of the nodes on surface $\mathrm{X}=0$ is restricted as $\mathrm{UX}=0$, likewise, the displacement of the nodes on surface $\mathrm{Y}=0$ is restricted as $\mathrm{UY}=0$. Simulations were carried out to prove that the model with quarter sized geometry is able to provide good results.

The augmented Lagrange method is used to seek contact in the simulations, and the large deformation is included during the calculation.

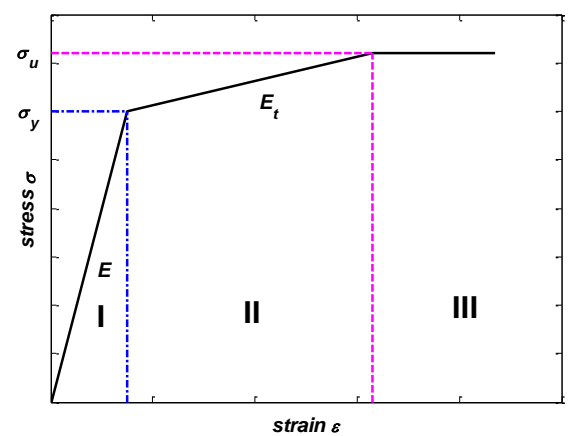

Fig. 3. Stress-strain curves for elastic-plastic material in FE models

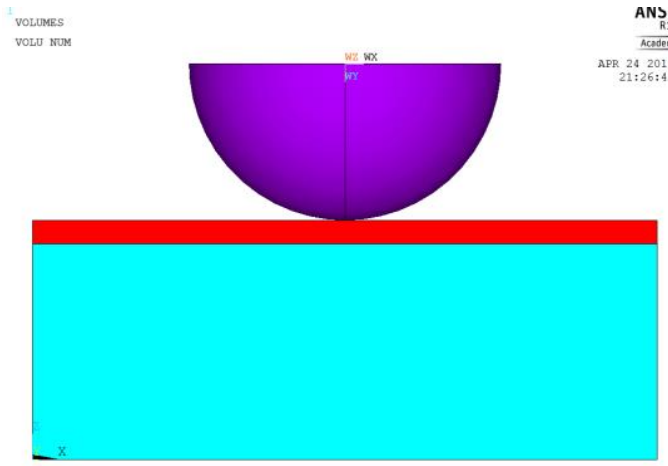

Fig. 4. Geometry of FE model with whole substrate size

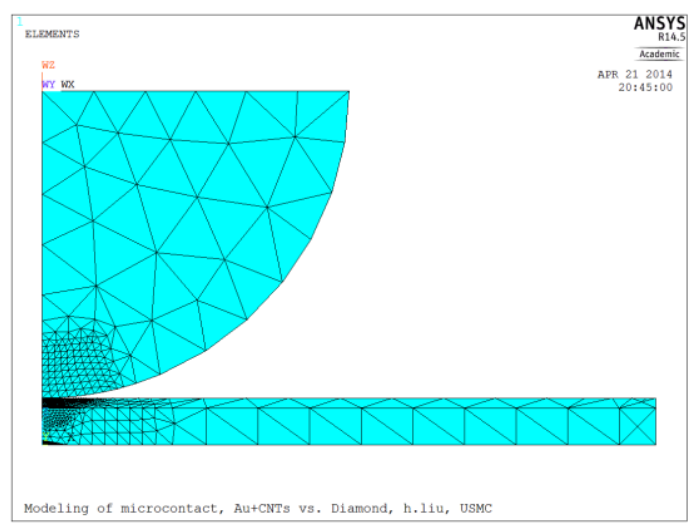

Fig. 5. Finite element mesh of the model with quarter sized geometry

\section{RESUlTS AND DISCUSSIONS}

\section{A. FEM results with Asssumption 1: single material}

Fig. 7 and Fig. 8 show the simulated results (labelled "FEM_Composite" in figures) with the samples of $300 \mathrm{~nm}$ gold coated on $30 \mu \mathrm{m}$ and $80 \mu \mathrm{m}$ CNTs respectively, and compared with the nanoindentation results. The maximum load

$0.25 \mathrm{mN}$. Here we denote $Z_{\text {res }}$ as the residual deformation after unloading, and $Z_{\max }$ as the maximum deformation at highest load. The simulations predict ratio of $Z_{\text {res }} / Z_{\max }$ much larger than the measurements $(0.66-0.82$ in FEM vs. $0.24-0.25$ in experiments). Also, the simulated slope at the unloading stage is much larger than that of experiments, especially for the sample with $30 \mu \mathrm{m}$ CNTs.

Fig. 6 shows the contours of deformation for sample $80 \mu \mathrm{m} \mathrm{CNTs} / 0.3 \mu \mathrm{m} \mathrm{Au}$ at load $0.25 \mathrm{mN}$. A minus UZ represents the deformation due to the downward contact pressure, so a plus UZ means that there is material pile-up. The simulations show that the pile up is found to be around the contact area, and the value can be up to several hundreds of $\mathrm{nm}$ for the soft samples, so it should be taken into account while calculating the contact area [20].

In brief, modeling the Au/CNTs as a unique composite cannot predict the mechanical behavior of Au/CNTs correctly. Considering the buckling and foam-like features of CNTs forest [15], the second assumption is proposed. 


\section{B. FEM results with Asssumption 2: multi-layered structure}

\section{1) First results with original setting}

The first simulations were carried out for samples with $300 \mathrm{~nm}$ gold coated. The penetration depth is assumed as $4.3 \mu \mathrm{m} \mathrm{[17],} \mathrm{which} \mathrm{is} \mathrm{set} \mathrm{as} \mathrm{the} \mathrm{thickness} \mathrm{of} \mathrm{the} \mathrm{top} \mathrm{layer.} \mathrm{The}$ thickness of CNTs forest is changed for different samples while keeping the total nominal thickness of samples unchanged. That is, sample $30 \mu \mathrm{m}$ CNTs/0.3 $\mu \mathrm{m} \mathrm{Au}$ is modeled as $26 \mu \mathrm{m}$ CNTs plus $4.3 \mu \mathrm{m}$ top layer, and likewise for others. Material properties are from the first two rows in Table II.

Fig. 7 and Fig. 8 show the simulations results (labeled "FEM_Multilayer") for samples $30 \mu \mathrm{m}$ CNTs/0.3 $\mu \mathrm{m} \mathrm{Au}$ and $80 \mu \mathrm{m} \mathrm{CNTs} / 0.3 \mu \mathrm{m} \mathrm{Au}$, respectively. Also shown are the experiments results and FE results with Assumption 1 (labeled "FEM_Composite"). The multi-layered model results matched well with the experiments for the sample with $80 \mu \mathrm{m}$ CNTs, but not for the sample with $30 \mu \mathrm{m}$ CNTs. However, the ratio of $Z_{\mathrm{res}} / Z_{\max }$ for the sample $30 \mu \mathrm{m}$ CNTs decreased from 0.66 with Assumption 1 to 0.34 with multi-layered model, which is much closer to 0.22 in experiments, which suggests that the multi-layered structure is a better approach.

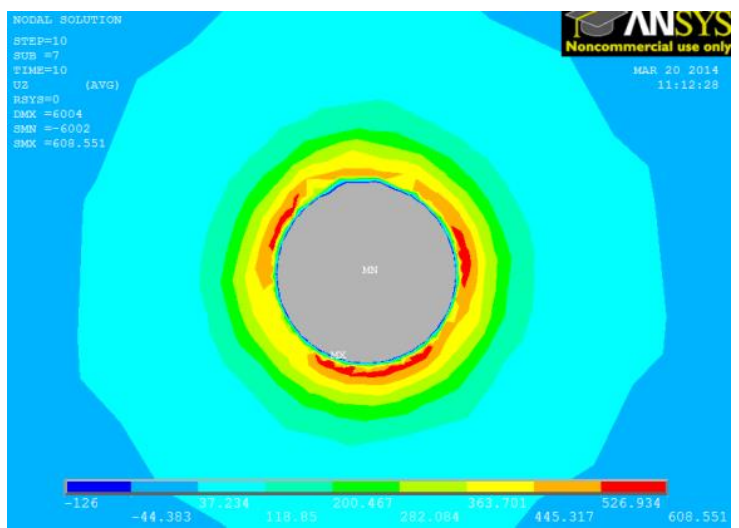

Fig. 6. Top view of contact deformation of contact surface at $0.25 \mathrm{mN}$ : zoom in the contact zone and pile-up area

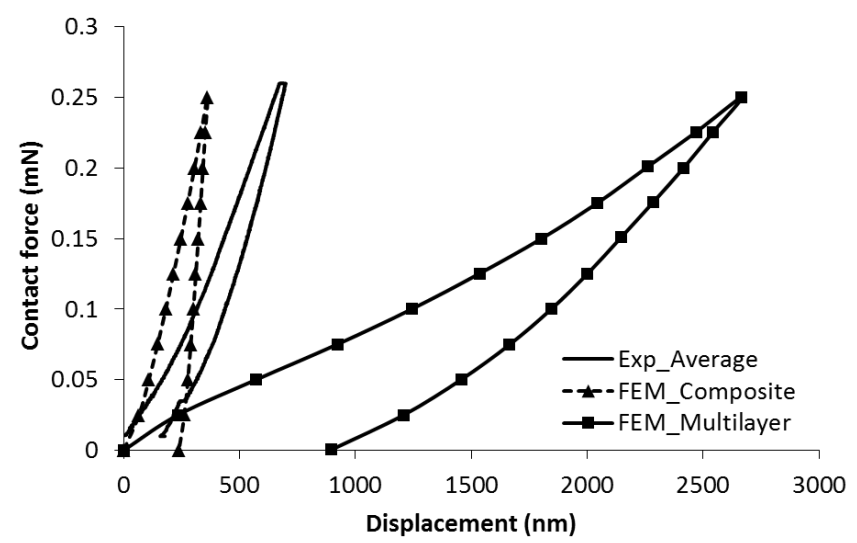

Fig. 7. Comparison between indentation test and FE models for the composite: $30 \mu \mathrm{m} \mathrm{CNTs} / 0.3 \mu \mathrm{m} \mathrm{Au}$ at $0.25 \mathrm{mN}$ load

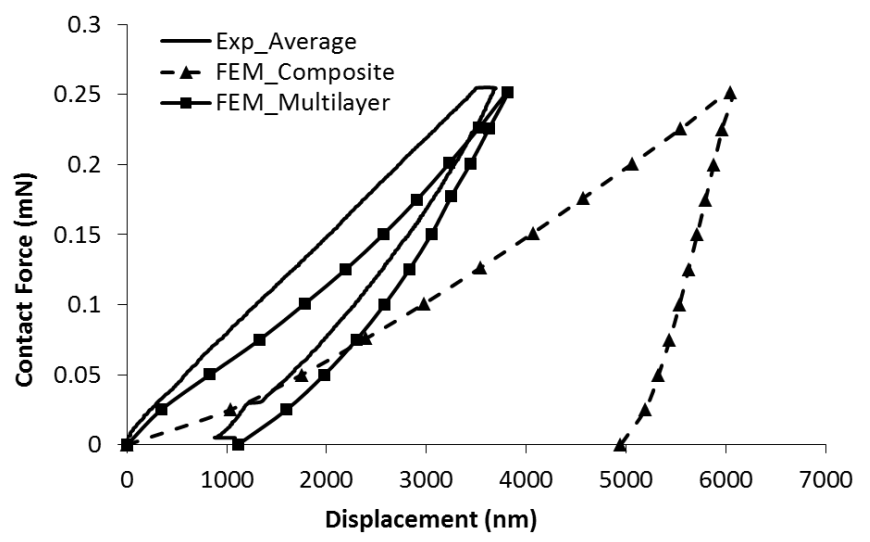

Fig. 8. Comparison between indentation test and FE models for the composite: $80 \mu \mathrm{m} \mathrm{CNTs} / 0.3 \mu \mathrm{m} \mathrm{Au}$ at $0.25 \mathrm{mN}$ load.

2) Discussion: Influence of material properteis

As discussed in part III, the material properties of the top layer and CNTs forest are approximations, and also the penetration depth is not certain, simulations were then carried out to investigate the influence of the material properties and the penetration depth, to find out the best fitted material properties and layer thickness.

The simulations were carried out for the sample $30 \mu \mathrm{m}$ $\mathrm{CNTs} / 0.3 \mu \mathrm{m} \mathrm{Au}$. The elastic modulus of the CNTs under layer was firstly multiplied by 5 , and then by 10 , the results are plotted in Fig. 9 (a). The varied material properties are listed in Table II. The notation used here is exemplified by "CNTs5" implying elastic modulus of CNTs multiplied by 5 . It was found that with larger elastic modulus in the under layer, less deformation is found on both the loading and unloading stage. And the model "CNTs10" shows better agreement with the experiments results than others.

To improve the fitting with the nanoindentation tests, the elastic modulus and hardness of the top layer are both multiplied by 2 , and then by 5 based on the model "CNTs10", nominated "Top1.4" and "Top5" respectively. The simulation results are plotted in Fig. 9 (b). It was found that the material setting "CNTs10Top1.4" matched best with the experiments results.

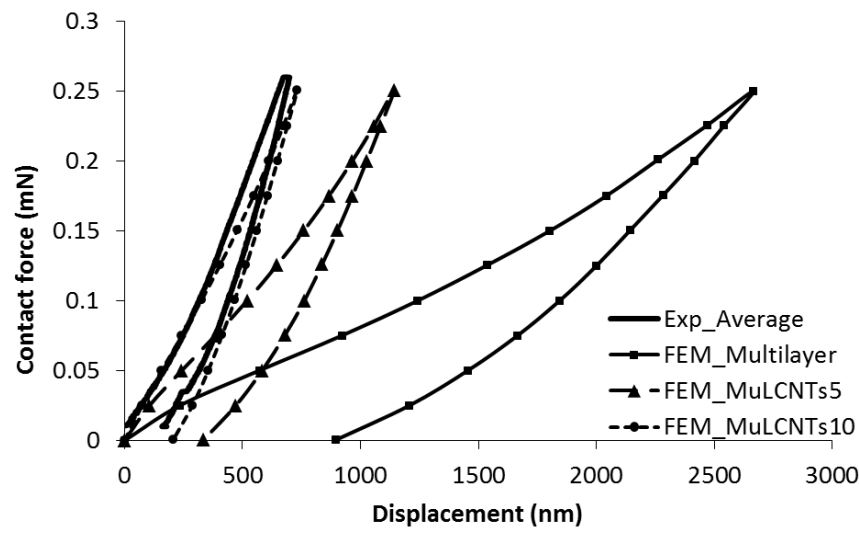

(a) 


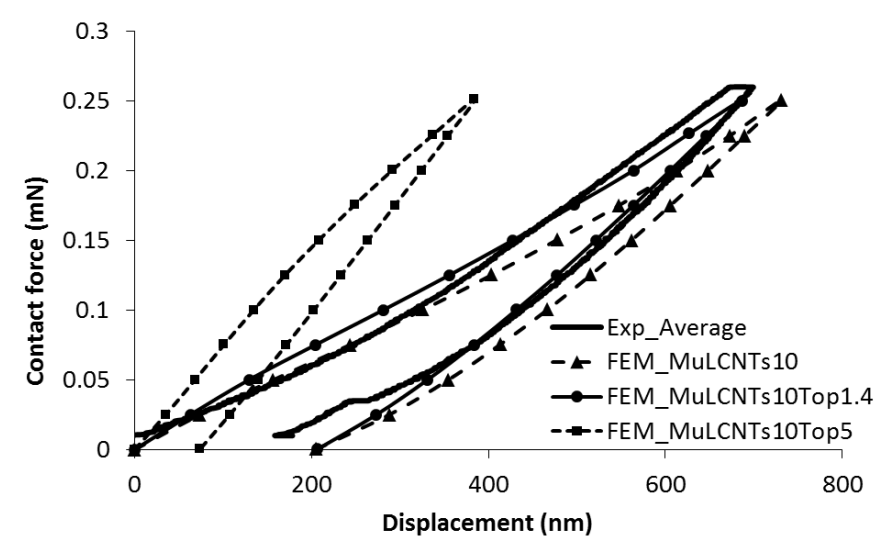

(b)

Fig. 9. Comparison between indentation test and multi-layered models for the composite $30 \mu \mathrm{m} \mathrm{CNTs} / 0.3 \mu \mathrm{m} \mathrm{Au}$ with varying material properties in simulations, the load is $0.25 \mathrm{mN}$.

To further validate the multi-layered model and the material properties, simulations are carried out for the same sample at load of $0.75 \mathrm{mN}$, and the results are shown in Fig. 10. The difference between simulation and experiments at $0.75 \mathrm{mN}$ is much larger than that at $0.25 \mathrm{mN}$. But the slopes of curves at unloading and the residual deformation are close.

Simulations at load of $0.75 \mathrm{mN}$ are also performed for the sample $80 \mu \mathrm{m} \mathrm{CNTs} / 0.3 \mu \mathrm{m}$ Au with the original properties setting which provided good results at $0.25 \mathrm{mN}$ (see Fig. 8). The results are plotted in Fig. 11. Although the slope of the curves is different at loading process, the slopes are very close at unloading process, and the residual and maximum deformation compare well with the experiments.

The simulations results show that the default material properties cannot be used for each sample. Indeed, the material properties of CNTs forest depend on the growth length and density, with shorter CNTs having higher effective elastic modulus [16]. The default properties for CNTs forest are from the $80 \mu \mathrm{m}$ CNTs samples, and probably not a good value for $30 \mu \mathrm{m}$ CNTs samples, so increasing the values of material properties for $30 \mu \mathrm{m}$ CNTs samples in the modeling was reasonable.

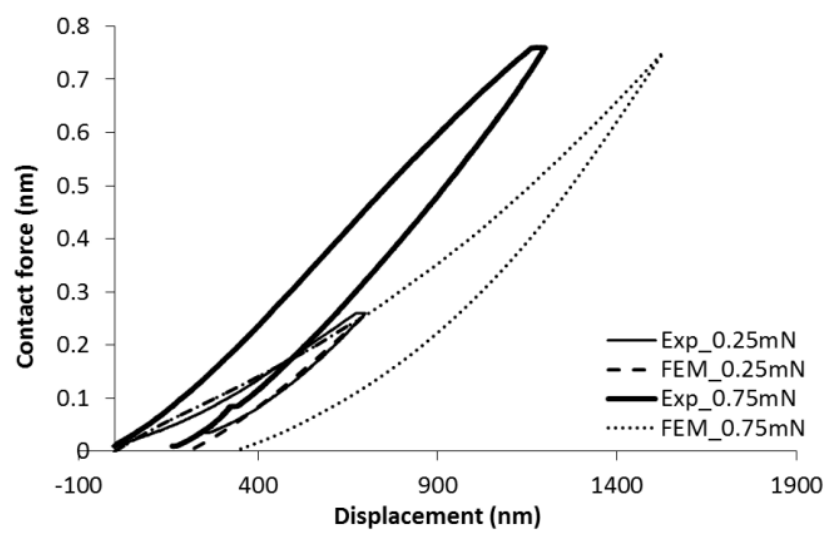

Fig. 10. Comparison between indentation test and FE models of

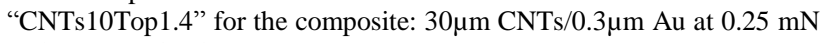
and $0.75 \mathrm{mN}$ load.

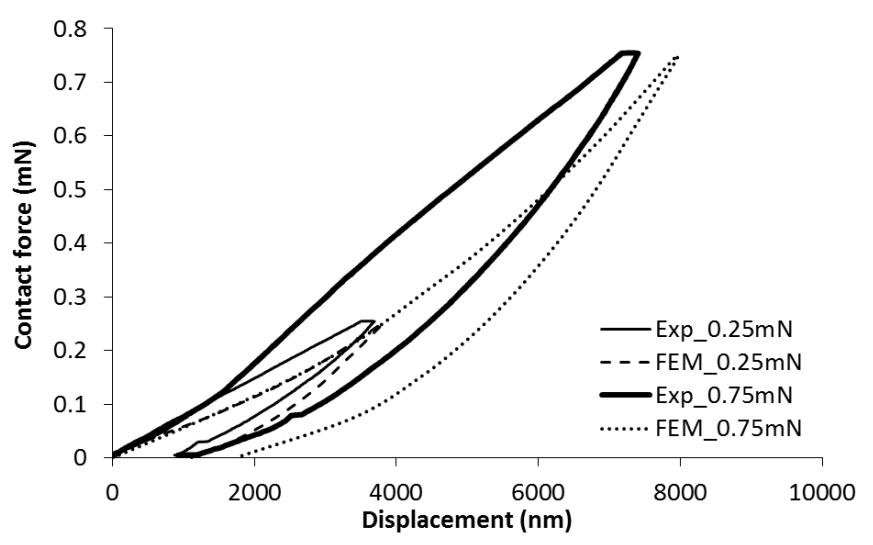

Fig. 11. Comparison between indentation test and FE models of original settingfor the composite: $80 \mu \mathrm{m} \mathrm{CNTs} / 0.3 \mu \mathrm{m}$ Au at $0.25 \mathrm{mN}$ and 0.75 $\mathrm{mN}$ load.

3) Discussion: Samples with varying Au layer thickness

For samples with different sputtered gold film coated on $30 \mu \mathrm{m} \mathrm{CNTs}$, the materials properties are the same as labeled "CNTs10Top1.4" which gave the best results for the sample $30 \mu \mathrm{m} \mathrm{CNTs} / 0.3 \mu \mathrm{m}$ Au. For different sputtered gold layer, penetration depths are varied while keeping the nominal total thickness of sample unchanged. With SEM image, it was found that gold penetration is deeper with more gold coated, so in FE models:

- $\quad$ Sample $30 \mu \mathrm{m}$ CNTs $/ 0.5 \mu \mathrm{m}$ Au is modeled as $6.5 \mu \mathrm{m}$ top layer and $24 \mu \mathrm{m}$ CNTs under layer.

- $\quad$ Sample $30 \mu \mathrm{m}$ CNTs $/ 0.8 \mu \mathrm{m}$ Au is modeled as $8.8 \mu \mathrm{m}$ top layer and $22 \mu \mathrm{m}$ CNTs under layer.

The results for the samples with $0.5 \mu \mathrm{m}$ and $0.8 \mu \mathrm{m} \mathrm{Au}$ at load $0.25 \mathrm{mN}$ and $0.75 \mathrm{mN}$ are plotted in Fig.12 and Fig.13, respectively. The simulations results match well with the experiments results for the sample with $0.5 \mu \mathrm{m} \mathrm{Au}$, but not for the sample with $0.8 \mu \mathrm{m} \mathrm{Au}$. A possible reason is that the penetration depth of gold is not large enough, so the thickness of top layer is multiplied by 1.5 in the FEM, and the results are plotted in Fig.14. The simulations results match better with the test, but the difference is larger than that with thinner gold. It was observed with SEM that more gold makes deeper into CNTs, but there is limited penetration depth [18], so there is probably a neat gold film formed with $800 \mathrm{~nm}$ gold coated, which makes the assumption of two layers not suitable, this will be addressed in further study.

With above discussion, it is found that with multi-layered assumption, by varying the material properties and penetration depth, modeling can give the force-displacement results very close to the experiments. However, with assumption 1, the simulated contact stiffness was always much higher than that of experimental data, good matching cannot be achieved with varying parameters in the modeling. This confirmed that the multi-layered structure is a good approach for Au/CNTs composite, which can enhance understand of the material properties of $\mathrm{Au} / \mathrm{CNT}$ composite. 
4) Discussion: Effective elastic modulus calculation

For multi-layered structure, it was found that the effective Young's modulus depends on the thickness of layers and the indenter depth in nanoindentation tests [22, 25-26, 29], especially for thin films. When the indenter depth is above the 0.2 to 0.3 time of the thickness of films, the influence of the substrate must be considered [26]. The effective Young's modulus can be calculated with the formula [25]:

$$
\frac{1}{E_{r}}=\frac{1-v_{i}^{2}}{E_{i}}+\frac{1-v_{f}^{2}}{E_{f}}\left(1-e^{-\alpha t / h_{c}}\right)+\frac{1-v_{s}^{2}}{E_{s}}\left(e^{-\alpha t / h_{c}}\right)
$$

where $f$ and $s$ refer to the film and substrate respectively, $t$ is the thickness of the thin film, and $\alpha$ is an unknown parameter. An empirically determined value of $\alpha$ can be used [31], where $\alpha=0.25$. For a spherical indentation, $h_{\mathrm{c}}$ can be evaluated by [20]:

$$
h_{c}=\frac{h_{\max }+h_{r e s}}{2}
$$

In our multi-layered model, the thickness of top layer is relatively small compared to the large indentation depth, so if we consider the top layer as a thin film, the CNTs forest is then the substrate. With the material properties used in models and the simulations results, the effective modulus of the $\mathrm{Au} / \mathrm{CNT}$ s can be evaluated with (4-5). The calculated results for samples with $300 \mathrm{~nm}$ gold coated layer on $30 \mu \mathrm{m}$ and 80 $\mu \mathrm{m}$ CNTs are listed in Table III. The calculations are based on the material setting which provided the best fitting with nanoindentation tests. The calculated values show a good agreement with the experimental data, which demonstrate the utility of the multi-layered model, and also show that the material properties of each layer can be obtained with the help of finite element modeling.

TABLE III. EFFETIVE MOdUlus CALCUATION WITH MULTI-LAYERED STRUCTURE THEORY, AND COMPARED WITH EXPERIMENTAL RESULTS, ALL THE DATA ARE BASED ON $0.25 \mathrm{MN}$

\begin{tabular}{|c|c|c|c|c|c|c|}
\hline Sample & $\begin{array}{c}\boldsymbol{E}_{f} \\
(\mathbf{M P a})\end{array}$ & $\begin{array}{c}\boldsymbol{E}_{\boldsymbol{s}} \\
(\mathbf{M P a})\end{array}$ & $\begin{array}{c}\boldsymbol{t} \\
(\boldsymbol{n m})\end{array}$ & $\begin{array}{c}\boldsymbol{h}_{\text {eff }} \\
(\mathbf{n m})\end{array}$ & $\begin{array}{c}\boldsymbol{E}_{\boldsymbol{r}} \\
(\mathbf{M P a})\end{array}$ & $\begin{array}{c}\boldsymbol{E}_{\text {exp }} \\
(\mathbf{M P a})\end{array}$ \\
\hline $\begin{array}{c}30 \mu \mathrm{m} \\
\mathrm{CNTs} / 0.3 \mu \mathrm{m} \\
\mathrm{Au}\end{array}$ & 1242.44 & 7.26 & 4300 & 468.2 & 68.694 & 66.483 \\
\hline $\begin{array}{c}80 \mu \mathrm{m} \\
\mathrm{CNTs} / 0.3 \mu \mathrm{m} \\
\mathrm{Au}\end{array}$ & 887.455 & 0.726 & 4300 & 2462.8 & 1.122 & 1.2909 \\
\hline
\end{tabular}

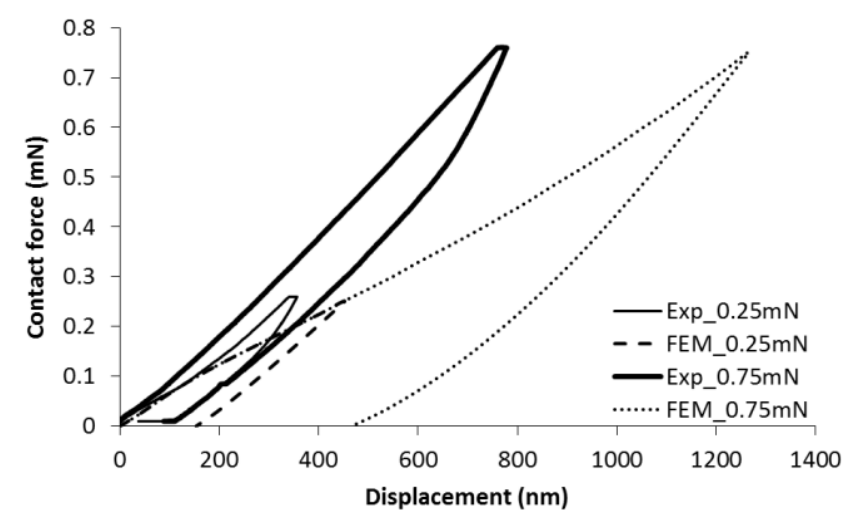

Fig.12. Comparison between indentation test and FE models of "CNTs10Top1.4" for the composite: $30 \mu \mathrm{m}$ CNTs/ $0.5 \mu \mathrm{m}$ Au at $0.25 \mathrm{mN}$ and $0.75 \mathrm{mN}$ load.

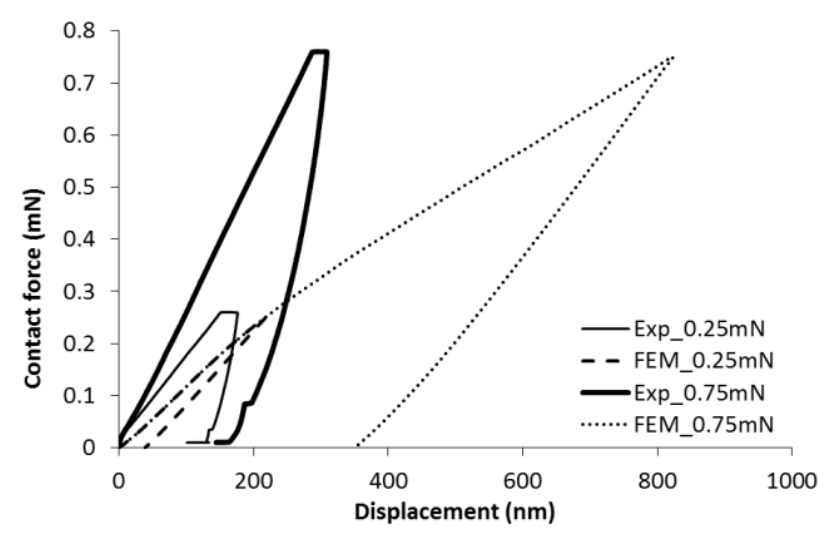

Fig.13. Comparison between indentation test and FE models of "CNTs10Top1.4" for the composite: $30 \mu \mathrm{m} \mathrm{CNTs} / 0.8 \mu \mathrm{m}$ Au at $0.25 \mathrm{mN}$ and $0.75 \mathrm{mN}$ load.

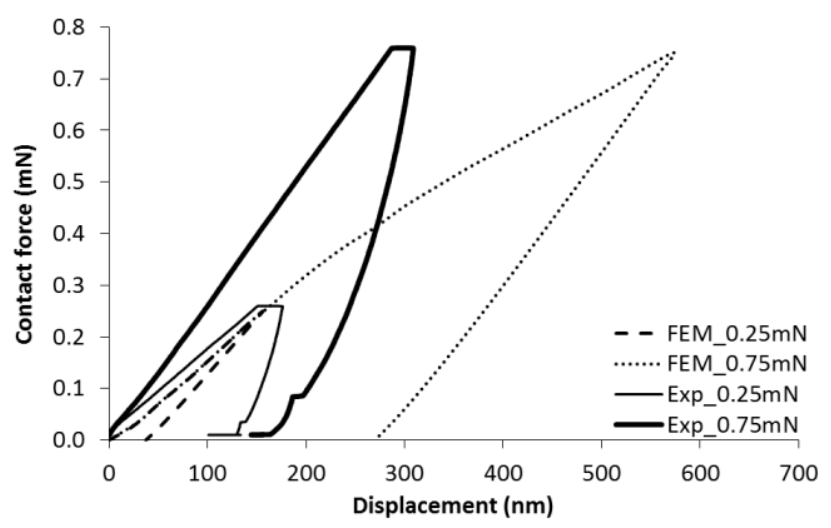

Fig.14. Comparison between indentation test and FE models of "CNTs10Top1.4" for the composite: $30 \mu \mathrm{m} \mathrm{CNTs} / 0.8 \mu \mathrm{m} \mathrm{Au}$ at $0.25 \mathrm{mN}$ and $0.75 \mathrm{mN}$ load, the penetration depth is increased to $13.2 \mu \mathrm{m}$.

\section{CONCLUSIONS}

This paper investigated the structure and material properties of gold coated carbon nanotube surfaces. The study showed that the surface is best to modeled as a multi-layered structure. Considering the unique feature of the surfaces, where gold penetrates partially into the CNTs forest, the top 
layer is modeled as a mixed elastic-plastic soft composite, and under layer as elastic pure CNTs. By varying the material properties and the layer thickness, the multi-layered model conformed to the mechanical behavior of the Au/CNTs composite well compared to the nanoindentation tests, while the single material model was not able to make good match with the experimental data. The multi-layered model showed good potential, and is an initial study towards the development of an analytical model. Furthermore, the multi-layered model can be used to understand the behavior of specific compositions of the composite and for tailoring the material properties to suit specific application needs.

For further investigation, the contact area will be extracted from the model and the contact resistance will be evaluated. This will allow the composite to be optimized in terms of contact resistance performance in MEMS microswitches.

\section{ACKNOWLEDGMENT}

This work was supported by the Innovative Electronics Manufacturing Research Centre (IeMRC) and Engineering and Physical Sciences Research Council (EPSRC) under grant number: EP/H03014X/1.

\section{REFERENCES}

[1] R. A. Coutu, J. R. Reid, R. Cortez, R. E. Strawser, and P. E. Kladitis, "Microswitches with sputtered Au, AuPd, Au-on-AuPt, and AuPtCu alloy electric contacts", IEEE Trans. Compon. Packag. Technol., vol. 29, no. 2, pp. 341-349, 2006.

[2] F. Ke, J. Miao, and J. Oberhammer, "A Ruthenium-Based MultimetalContact RF MEMS Switch With a Corrugated Diaphragm", J. Microelectromechanical Syst., vol. 17, no. 6, pp. 1447 -1459, Dec. 2008.

[3] A. Broue et al., "Multi-Physical Characterization of Micro-Contact Materials for MEMS Switches", in Proceedings of the 56th IEEE Holm Conference on Electrical Contacts, Charleston, SC, 2010, pp. 1-10.

[4] B. F. Toler, R. A. Coutu, and J. W. McBride, "A review of microcontact physics for microelectromechanical systems (MEMS) metal contact switches", J. Micromechanics Microengineering, vol. 23, no. 10, p. 103001 , Oct. 2013.

[5] J. W. McBride, E. M. Yunus, and S. M. Spearing, "Improving the contact resistance at low force using gold coated carbon nanotube surfaces", Eur. Phys. J. - Appl. Phys., vol. 50, no. 01, p. 12904 (6 pages), 2010.

[6] E. M. Yunus, J. W. McBride, and S. M. Spearing, "The Relationship between Contact Resistance and Contact Force on Au coated Carbon Nanotube surfaces", in Proceedings of The 53rd IEEE Holm Conference on Electrical Contacts, 2007, pp. 167-174.

[7] E. Yunus, M. Spearing, and J. McBride, "Investigation of gold sputter coated vertically aligned multi-walled carbon nanotubes for RF MEMS contact surfaces", Materials Research Society Symposium; Microelectromechanical Systems-Materials and Devices II. MRS Fall Meeting, Warrendale, PA, USA (MRS Proceedings 1139), 2008.

[8] J. W. McBride, C. Chianrabutra, L. Jiang, and S. H. Pu, "The contact resistance performance of gold coated carbon-nanotube surfaces under low current switching", In the 12th International Session on ElectroMechanical Devices (IS-EMD2012), 8pp, 30-Nov-2012.

[9] J. W. McBride, S. M. Spearing, L. Jiang, and C. Chianrabutra, "Gold Coated Carbon-Nanotube Surfaces as Low Force Electrical Contacts for MEMS Devices: Part II, Fine Transfer Mechanisms", in IEEE 57th Holm Conference on Electrical Contacts (Holm), 2011, pp. 1-6.

[10] C. Chianrabutra, L. Jiang, A. P. Lewis, and J. W. McBride, "Evaluating the Influence of Current on the Wear Processes of $\mathrm{Au} / \mathrm{Cr}-\mathrm{Au} / \mathrm{MWCNT}$ Switching Surfaces", in $59^{\text {th }}$ IEEE Holm Conference on Electrical Contacts (HOLM), 2013, pp. 1-6.
[11] H. J. Qi et al., "Determination of mechanical properties of carbon nanotubes and vertically aligned carbon nanotube forests using nanoindentation", J. Mech. Phys. Solids, vol. 51, no. 11-12, pp. 2213 2237, Nov. 2003.

[12] B. I. Yakobson and P. Avouris, "Mechanical Properties of Carbon Nanotubes", in Carbon Nanotubes, M. S. Dresselhaus, G. Dresselhaus, and P. Avouris, Eds. Springer Berlin Heidelberg, 2001, pp. 287-327.

[13] R. S. Ruoff, D. Qian, and W. K. Liu, "Mechanical properties of carbon nanotubes: theoretical predictions and experimental measurements", Comptes Rendus Phys., vol. 4, no. 9, pp. 993-1008, Nov. 2003.

[14] N. J. Ginga, W. Chen, and S. K. Sitaraman, "Waviness reduces effective modulus of carbon nanotube forests by several orders of magnitude", Carbon, vol. 66, pp. 57-66, Jan. 2014.

[15] A. Cao, P. L. Dickrell, W. G. Sawyer, M. N. Ghasemi-Nejhad, and P. M. Ajayan, "Super-Compressible Foamlike Carbon Nanotube Films", Science, vol. 310, no. 5752, pp. 1307-1310, Nov. 2005.

[16] Y. Gao, T. Kodama, Y. Won, S. Dogbe, L. Pan, and K. E. Goodson, "Impact of nanotube density and alignment on the elastic modulus near the top and base surfaces of aligned multi-walled carbon nanotube films”, Carbon, vol. 50, no. 10, pp. 3789-3798, Aug. 2012.

[17] E. M. Yunus, J. W. McBride, and S. M. Spearing, "The Relationship Between Contact Resistance and Contact Force on Au-Coated Carbon Nanotube Surfaces Under Low Force Conditions", IEEE Trans. Compon. Packag. Technol., vol. 32, pp. 650-657, Sep. 2009.

[18] O. Yaglioglu, R. Martens, A. Cao, and A. H. Slocum, "Compliant Carbon Nanotube-Metal Contact Structures", in 57th IEEE Holm Conference on Electrical Contacts (Holm), 2011, pp. 1-5.

[19] M. P. Down, L. Jiand and J.W. McBride, "Mechanical Characterisation and Optimisation of Carbon Nanotube Composite Surfaces for Electrical Contact", 27th International Conference on Electrical Contacts (ICEC 2014), Dresden, Germany, in press.

[20] W. Oliver and G. Pharr, "Measurement of hardness and elastic modulus by instrumented indentation: Advances in understanding and refinements to methodology", J. Mater. Res., vol. 19, no. 01, pp. 3-20, 2004.

[21] www.microstartech.com/index/ConicalIndenters2.pdf

[22] R. Saha and W. D. Nix, "Effects of the substrate on the determination of thin film mechanical properties by nanoindentation", Acta Mater., vol. 50, no. 1, pp. 23-38, Jan. 2002.

[23] F. T. Fisher, R. D. Bradshaw, and L. C. Brinson, "Effects of nanotube waviness on the modulus of nanotube-reinforced polymers", Appl. Phys. Lett., vol. 80, no. 24, pp. 4647-4649, Jun. 2002.

[24] L. Kogut and I. Etsion, "Elastic-plastic contact analysis of a sphere and a rigid flat”, J. Appl. Mech., vol. 69, pp. 657-662, 2002.

[25] R. B. King, "Elastic analysis of some punch problems for a layered medium”, Int. J. Solids Struct., vol. 23, no. 12, pp. 1657-1664, 1987.

[26] W. Peng and B. Bhushan, "A Numerical Three-Dimensional Model for the Contact of Layered Elastic/Plastic Solids with Rough Surfaces by a Variational Principle", J. Tribol., vol. 123, pp. 330-342, 2001.

[27] Y. Won, Y. Gao, M. A. Panzer, S. Dogbe, L. Pan, T. W. Kenny, and K. E. Goodson, "Mechanical characterization of aligned multi-walled carbon nanotube films using microfabricated resonators", Carbon, vol. 50, no. 2, pp. 347-355, Feb. 2012.

[28] M. R. Maschmann, Q. Zhang, F. Du, L. Dai, and J. Baur, "Length dependent foam-like mechanical response of axially indented vertically oriented carbon nanotube arrays", Carbon, vol. 49, no. 2, pp. 386-397, Feb. 2011.

[29] A. K. Bhattacharya and W. D. Nix, "Analysis of elastic and plastic deformation associated with indentation testing of thin films on substrates”, Int. J. Solids Struct., vol. 24, no. 12, pp. 1287-1298, 1988.

[30] H. Liu, D. Leray, S. Colin, P. Pons, and A. Broué, "Finite Element Based Surface Roughness Study for Ohmic Contact of Microswitches", in 58th IEEE Holm Conference on Electrical Contacts (Holm), Portland, OR, 2012, pp. 1-10.

[31] M. F. Doerner and W. D. Nix, "A method for interpreting the data from depth-sensing indentation instruments", J. Mater. Res., vol. 1, no. 04, pp. 601-609,1986. 
